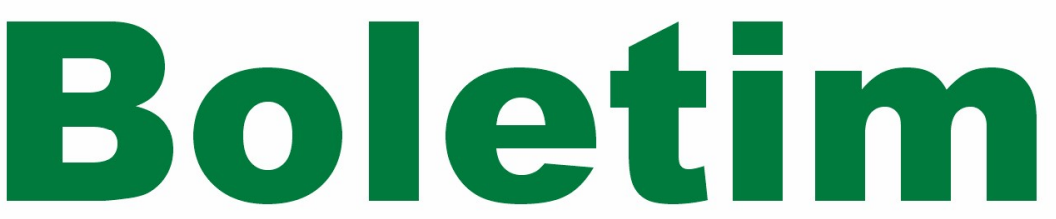

T É C N I C O S I F Número 01 Nolume 01

Motivos da inviabilidade de pares de cruzamentos controlados de Eucalyptus

Genaina Aparecida de Souza et al. 
ISSN 2763-6860

\title{
MOTIVOS DA INVIABILIDADE DE PARES DE CRUZAMENTOS CONTROLADOS DE EUCALYPTUS
}

\author{
Genaina Aparecida de Souza ${ }^{1 *}$, Karoliny do Carmo Gandra ${ }^{2}$, Gleison Augusto dos Santos ${ }^{3}$, Elizabete Keiko
} Takahashi $^{4}$ e Fernando Palha Leite ${ }^{4}$

\footnotetext{
${ }^{1}$ Universidade Federal de Viçosa, Doutora em Fisiologia Vegetal, Viçosa < MG - Brasil . E-mail: <genainasouza@yahoo.com.br>.

${ }^{2}$ Universidade Federal de Viçosa, Graduanda em Engenharia Florestal, Viçosa MG- Brasil. E-mail: <karoliny.gandra@ufv.br>.

${ }^{3}$ Universidade Federal de Viçosa, Departamento de Engenharia Florestal, Viçosa MG- Brasil. E-mail: <gleison@ufv.br>

${ }^{4}$ Celulose Nipo Brasileira S.A, Cenibra, Belo Oriente, MG - Brasil. E-mail: <elizabete.takahashi@cenibra.com.br> e < fernando.leite@ cenibra.com.br>.

*Corresponding author.
}

RESUMO - O gênero Eucalyptus ocupa uma extensa área no Brasil, com grande importância econômica. Dentro de programas de melhoramento, a propagação por sementes é viável e utilizada comercialmente, principalmente por pequenos viveiros de mudas e também para produção de jardins clonais. $O$ objetivo desse estudo foi avaliar alterações anatômicas em sementes oriundas de diversos cruzamentos de Eucalyptus. Foram coletados botões florais/frutos de quatro diferentes materiais genéticos (E. grandis; E. urophylla; E. urophylla $\boldsymbol{x} \boldsymbol{E}$. grandis; E. urophylla autofecundado). As coletas foram realizadas a cada 15 dias, a partir da antese, sendo coletadas de cruzamentos consideradas de boa e má produção de sementes. Os materiais que foram autofecundados originavam poucas sementes e algumas inviáveis. As amostras coletadas foram fixadas em FAA50 (formaldeido, ácido acético, etanol a 50\% - 1: 1: 18 - volume:volume), foram armazenados em etanol a $70 \%$. Em seguida, desidratadas em séries etanólicas e incluidas em resina metacrilato (Historesin-Leica). As amostras foram cortadas em um micrótomo rotativo de avançado automático (modelo RM2155, Leica microsystems Inc., Deerfield, EUA), com espessura de 5 um. Para determinação das características anatômicas, as imagens foram obtidas em um microscópio acoplado a uma câmera e (modelo AX-70 TRF, Olympus Optical, Tóquio, Japão). Observamos que os botões florais que apresentavam maior lignificação originavam sementes com ovário funcional com os lóculos reduzidos. O que contribuiu para formação de sementes inviáveis, com tegumento espessado e células do endosperma anormais. Quando era possível observar a formação do ovário, este era constituído de tecidos altamente lignificados, com muitos esclereídes. Já os botões florais com menor lignificação, apresentavam ovários com lóculos bem desenvolvidos, para abrigar as sementes de aparência normal, com tegumento constituido de apenas uma camada e endosperma com células bem delimitadas $e$ nucleadas. Assim, concluímos que nossos resultados evidenciam que alterações anatômicas, provavelmente de caráter genético, incompatibilidade, geram sementes inviáveis elou em baixa quantidade, dificultando a realização de determinados cruzamentos de interesse.

Palavras-Chave: Híbridos de Eucalipto, anatomia; botão floral; sementes.

Boletim Técnico SIF 2021:01

Bol.Téc.SIF,Viçosa-MG,V01.N01.p.1-5,2021 http://dx.doi.org/10.53661/2763-686020210000001 


\section{INTRODUÇÃO}

O Brasil é um dos países mais desenvolvidos no setor florestal, com alta produtividade e menor custo de produção em relação a outros países do mundo. Esse quadro é devido aos avanços tecnológicos como introdução de material genético melhorado, mecanização das atividades florestais e condições edafoclimáticas favoráveis à produção de madeira e seus derivados (SANTOS et al., 2017). O gênero Eucalyptus ocupa a maior área de exploração e possui a maior produção de madeira em relação às outras espécies (IBGE, 2018). Além da sua importância dentro de programas de melhoramento, para estudos de adaptação e caracterização de plantas, a propagação por sementes é viável e utilizada comercialmente, principalmente por pequenos viveiros de mudas e também para produção de jardins clonais (MARTINS et al., 2014).

O melhoramento genético e, especialmente, os cruzamentos controlados são técnicas eficientes de se conseguir materiais genéticos com as características desejadas, como maior incremento anual, resistência a pragas, dentre outras (PEREIRA, 2002; FONSECA et al., 2010). A polinização controlada permite reunir características superiores desejadas, como maior produção de madeira, maior resistência a pragas e a fenômenos naturais, bem como, menor teor de lignina para a produção de celulose. Gera-se assim indivíduos com características superiores provenientes de diferentes indivíduos selecionados (ASSIS, 1993; PEREIRA, 2002). No entanto, alguns cruzamentos geram sementes inviáveis e/ou em baixa quantidade.

No melhoramento florestal de Eucalytpus a hibridação desempenhou e continuará desempenhando papel importante na obtenção de material genético altamente produtivo e resistente à pragas e doenças. Um exemplo bem conhecido é o E. urograndis, resultado do cruzamento de Eucalytpus grandis x Eucalytpus urophylla que tem sido amplamente utilizado em diversas regiões do Brasil pelas suas características de produtividade interessantes, especialmente para indústria de papel e celulose. A possibilidade de obtenção de outros híbridos promissores é muito grande para esse gênero. No entanto, a hibridação só é bem sucedida com o adequado manejo do pólen e quando há compatibilidade entre os materiais utilizados. A produção de sementes inviáveis para muitas espécies é atribuída a essa incompatibilidade entre os materiais utilizados. Mas o que causa a baixa germinação ou a ausência dela após a semente ser formada ainda é um mistério. O objetivo desse estudo foi avaliar anatomicamente as sementes oriundas de diversos cruzamentos de Eucalyptus.

\section{MATERIAL E MÉTODOS}

Foram coletados botões florais/ frutos de quatro diferentes materiais genéticos (E. grandis; $E$. urophylla; E. urophylla $x$ E. grandis; E. urophylla autofecundado), de acordo com a tabela 1. As coletas foram realizadas a cada 15 dias, sendo coletadas amostras consideradas de boa e má produção de sementes após a polinização de cada espécie. Em cada coleta, pelo menos 15 botões florais/frutos de cada material genético foi colhido a cada 15 dias (da antese até a formação de sementes). Em seguida foram fixados em FAA50 (formaldeído, ácido acético, etanol a 50\% - 1: 1: 18 - volume: volume) e enviados ao laboratório de Anatomia Vegetal da UFV. Após passarem por $48 \mathrm{~h}$ de vácuo foram armazenados em etanol a 70\% (Johansen, 1940). Em seguida, o material vegetal foi desidratado em séries etanólicas e incluído no metacrilato (Historesin-Leica), de acordo com as recomendações do fabricante. As amostras foram cortadas em um micrótomo rotativo avançado automático (modelo RM2155, Leica microsystems Inc., Deerfield, EUA) com espessura de $5 \mu \mathrm{m}$. As seções foram coradas com azul de toluidina em tampão fosfato, pH 6,5 (O’Brien e Mccully 1981). As lâminas de vidro foram montadas com resina sintética (Permount $\left.{ }^{\circledR}\right)$. Para determinação das características anatômicas, as imagens foram obtidas em um misoscoscope leve (modelo AX-70 TRF, Olympus Optical, Tóquio, Japão), acoplado a uma câmera digital (modelo Zeiss AxioCam HRc, Göttinger, Alemanha) e um microcomputador com o AxioVision ${ }^{\circledR}$ programa de captura de imagem.

\section{RESULTADOS E DISCUSSÃO}

Observamos que os botões florais oriundos de cruzamentos considerados ruins para produção de sementes não apresentavam ovário funcional com os lóculos presentes (Fig. 1A e 1C). A não observação de ovários funcionais pode ser um dos fatores que contribuíram para formação de sementes inviáveis, pois pode ter impedido o crescimento e desenvolvimento das sementes. Outra possibilidade já

Boletim Técnico SIF 2021:01 
Tabela 1 - Cronograma de coleta dos cruzamentos avaliados.

\begin{tabular}{|c|c|c|c|c|c|c|c|c|}
\hline$\overline{\text { Coleta }}$ & (GRA) & (GRA) & (URO) & (URO) & (UROxGRA) & (UROxGRA) & $\begin{array}{c}\text { (URO) } \\
\text { Autofecundado } \\
\end{array}$ & $\begin{array}{r}\text { (URO) } \\
\text { Autofecundado } \\
\end{array}$ \\
\hline $10 / 01 / 2018$ & $\mathrm{C} 1$ & - & $\mathrm{C} 1$ & $\mathrm{C} 1$ & $\mathrm{C} 1$ & - & - & - \\
\hline $25 / 01 / 2018$ & $\mathrm{C} 2$ & - & $\mathrm{C} 2$ & $\mathrm{C} 2$ & $\mathrm{C} 2$ & - & Autofecundação & - \\
\hline $06 / 02 / 2018$ & $\mathrm{C} 3$ & - & - & $\mathrm{C} 3$ & $\mathrm{C} 3$ & - & ATC1 & - \\
\hline $28 / 02 / 2018$ & $\mathrm{C} 4$ & $\mathrm{C} 1$ & $\mathrm{C} 3$ & $\mathrm{C} 4$ & $\mathrm{C} 4$ & $\mathrm{C} 1$ & ATC2 & - \\
\hline $14 / 03 / 2018$ & $\mathrm{C} 5$ & $\mathrm{C} 2$ & $\mathrm{C} 4$ & $\mathrm{C} 5$ & $\mathrm{C} 5$ & $\mathrm{C} 2$ & ATC3 & Autofecundação \\
\hline$\ldots$ & $\ldots$ & $\ldots$ & $\ldots$ & $\ldots$ & $\ldots$ & $\ldots$ & $\ldots$ & $\ldots$ \\
\hline $06 / 06 / 2018$ & $\mathrm{C} 11$ & $\mathrm{C} 8$ & $\mathrm{C} 10$ & $\mathrm{C} 11$ & $\mathrm{C} 11$ & $\mathrm{C} 8$ & ATC9 & ATC6 \\
\hline $20 / 06 / 2018$ & $\mathrm{C} 12$ & C9 & C11 & $\mathrm{C} 12$ & $\mathrm{C} 12$ & C9 & ATC10 & ATC7 \\
\hline $04 / 07 / 2018$ & $\mathrm{C} 13$ & $\mathrm{C} 10$ & $\mathrm{C} 12$ & $\mathrm{C} 13$ & $\mathrm{C} 13$ & C10 & ATC11 & $\overline{\text { ATC8 }}$ \\
\hline $18 / 07 / 2018$ & C14 & C11 & $\mathrm{C} 13$ & $\mathrm{C} 14$ & C14 & C11 & ATC12 & $\overline{\text { ATC9 }}$ \\
\hline $01 / 08 / 2018$ & $\mathrm{C} 15$ & $\mathrm{C} 12$ & $\mathrm{C} 14$ & $\mathrm{C} 15$ & $\mathrm{C} 15$ & $\mathrm{C} 12$ & ATC13 & $\overline{\mathrm{ATC} 10}$ \\
\hline $15 / 08 / 2018$ & $\mathrm{C} 16$ & $\mathrm{C} 13$ & $\mathrm{C} 15$ & $\mathrm{C} 16$ & C16 & $\mathrm{C} 13$ & ATC14 & - \\
\hline $29 / 08 / 2018$ & $\mathrm{C} 17$ & $\mathrm{C} 14$ & $\mathrm{C} 16$ & $\mathrm{C} 17$ & $\mathrm{C} 17$ & $\mathrm{C} 14$ & ATC15 & - \\
\hline $12 / 09 / 2018$ & $\mathrm{C} 18$ & $\mathrm{C} 15$ & $\mathrm{C} 17$ & $\mathrm{C} 18$ & $\mathrm{C} 18$ & $\mathrm{C} 15$ & ATC16 & - \\
\hline $26 / 09 / 2018$ & $\mathrm{C} 19$ & $\mathrm{C} 16$ & $\mathrm{C} 18$ & $\mathrm{C} 19$ & C19 & $\mathrm{C} 16$ & ATC17 & - \\
\hline $10 / 10 / 2018$ & $\mathrm{C} 20$ & $\mathrm{C} 17$ & $\mathrm{C} 19$ & $\mathrm{C} 20$ & $\mathrm{C} 20$ & $\mathrm{C} 17$ & ATC18 & - \\
\hline
\end{tabular}

estudada anteriormente é a incompatibilidade entre: o pólen e o pistilo (Ellis e Sedgley, 1992); diferenças nos tamanhos, número de óvulos e sementes por flor, peso de sementes (Langkamp 1987) ou ainda morfologia do estigma (Boland e Sedgley 1986), morfologia da antera (Bentham 1867; Blakely 1934) e disposição dos óvulos no ovário (Carr e Carr 1962).

Ainda em relação aos nossos resultados, quando era possível observar a formação do ovário, este era constituído de tecidos altamente lignificados, com muitos esclereídes (Fig. 1E). Além disso, as poucas "sementes" presentes não eram normais, apresentando tegumento espesso, ausência de endosperma constituído de células normais (Fig. 1E e 1G). A imensa diferença na morfologia de sementes de diferentes espécies de eucalipto (Luqman et al., 2018), sugere que essa diversidade pode estar envolvida na compatibilidade entre as espécies e na formação de sementes. Como por exemplo a redução de sementes pelo crescimento dos tubos polínicos de E. globulus que ultrapassam os ovários de E. nitens (Larcombe et al., 2016).

Já os botões florais oriundos de cruzamentos considerados eficientes na produção de sementes, apresentavam menor lignificação, ovários com lóculos bem desenvolvidos (Fig. 1B), para abrigar as sementes de aparência normal (Fig. 1B, 1D, 1F, $1 \mathrm{H}$ ), tegumentos uni seriado (compostos de uma única camada de células), de espessura normal (Fig.
1F e 1H), endosperma com células bem delimitadas (Fig. 1H). Nesse caso, observamos que a fertilização ocorreu de forma positiva, originando sementes viáveis. Isso pode ser atribuído a diversos fatores, como observado em Eucalyptus woodwardii, que a quantidade de secreção do estigma e capacidade de suportar germinação do pólen e crescimento do tubo polínico aumentou com o tempo, atingindo um pico 7 dias após antese (He et al., 2017). Além disso, a alta compatibilidade entre os genótipos utilizados e ao bom desenvolvimento do ovário que permitiu o crescimento das sementes.

\section{CONCLUSÕES}

Nesse trabalho os principais fatores que parecem causar a inviabilidade de sementes oriundas de pares de cruzamentos controlados de Eucalyptus são: Alterações na morfologia e anatomia das sementes, levando a anomalias no tegumento, como maior espessamento das células, que aumenta a barreira mecânica para germinação. Além de células do endosperma mal formadas, sem nucleação e sem parede celular uniforme. Enquanto pares de cruzamentos que geram sementes com tegumento uni seriado, pouco espesso e com endosperma com células normais, são capazes de armazenar substâncias de reserva e originam sementes viáveis.

Como possíveis ações para mitigar os problemas de inviabilidade das sementes, podemos sugerir 

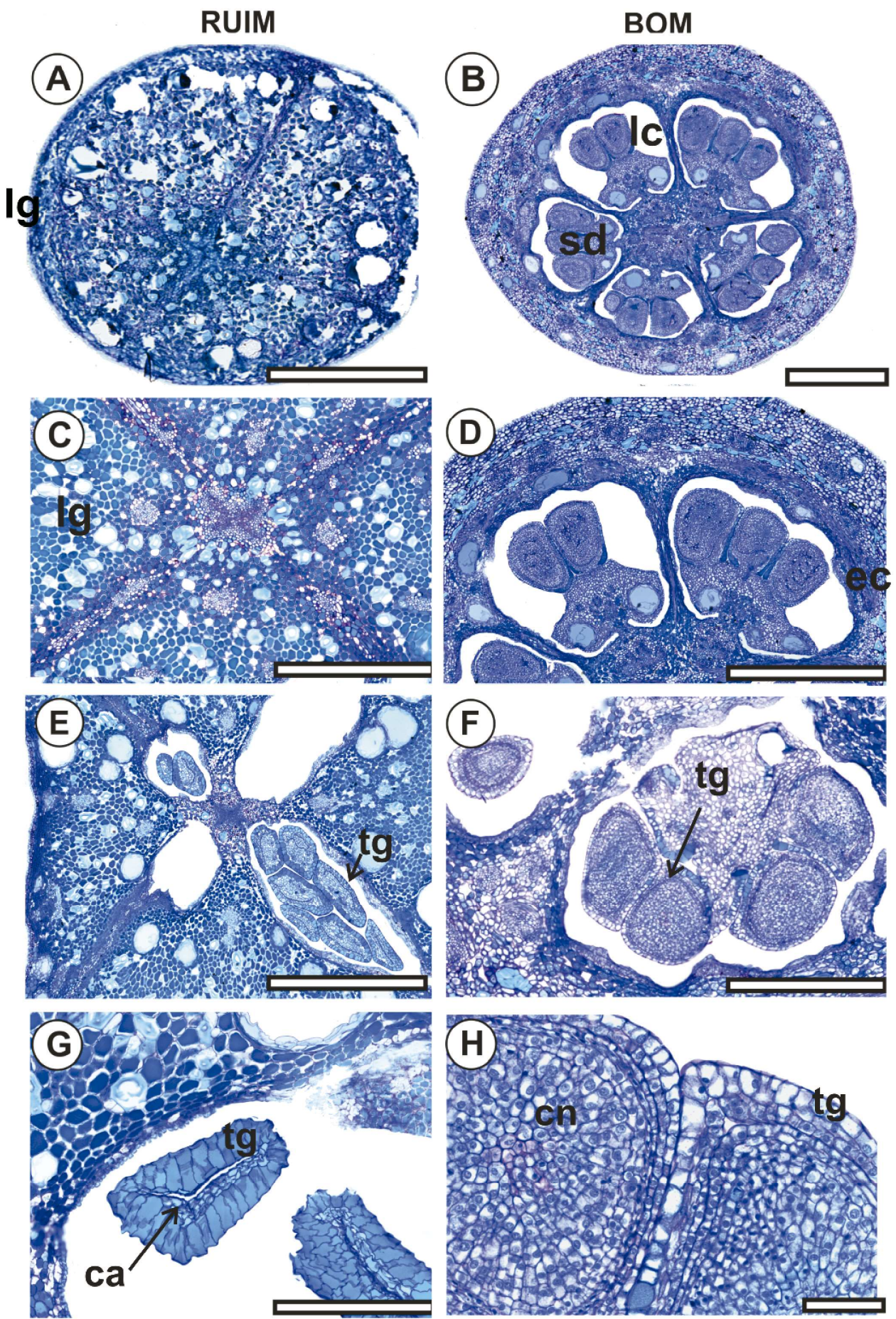

Figura 1 - Cortes transversais de botões florais de Eucalyptus oriundos de diferentes cruzamentos. A, C, E e G: botões florais de cruzamentos que geram sementes inviáveis. $B, D, F$ e H: botões florais de cruzamentos que geram sementes viáveis. Barras: A e $B=1000 \mu \mathrm{m} ; C-F=500$ um e $G$ e $H=250 \mu \mathrm{m}$. lg= tecido lignificado: $l c=$ lóculo do ovário: $s d=$ semente em desenvolvimento; $e c=$ células esclerificadas; $t g=$ tegumento; $c a=$ células anormais no endosperma e cn= células normais no endosperma. 
a utilização de reguladores de crescimento como auxinas, citocininas e giberelinas. Esses reguladores, em baixas concentrações, aplicados durante o desenvolvimento dos primórdios florais, podem favorecer o desenvolvimento dos tecidos do ovário. Assim, auxiliando na fertilização e desenvolvimento das sementes, contribuindo para a obtenção de sementes viáveis em pares de cruzamentos onde há dificuldade de se conseguir sementes para produção de mudas e instalação de testes de progênies.

\section{AGRADECIMENTOS}

Cenibra, SIF, Capes e UFV.

\section{REFERÊNCIAS BIBLIOGRÁFICAS}

ASSIS Teotônio et al. (1993). Sintetização de híbridos de Eucalyptus por cruzamentos controlados. Ciência Florestal, Santa Maria, v.3, n.1, 1993.

Blakely (1934). 'A Key to the Eucalypts.' (The Workers Trustee: Sydney.)

Bentham (1867). 'Eucalyptus.' Flora Australiensis 3, 185-261.

Boland and Sedgley M. (1986). Stigma and style morhology in relation to taxonomy and breeding system in Eucalyptus and Angophora (Myrtaceae). Australian Journal of Botany 34,569- 84.

Carr and Carr (1969). Oil glands and ducts in Eucalyptus L'HCrit. I. The phloem and the pith. Australian Journal of Botany 17,471-513.

Ellis and Sedgley M. (1992) Floral Morphology and Breeding System of Three Species of Eucalyptus, Section Bisectaria (Myrtaceae). Aust. J. Bot., 1992,40,249-62.

Fonseca et al. (2010). Manual prático de melhoramento genético do eucalipto. Viçosa, MG: UFV. Pág. 13-114.
He et al. (2017). Pollen viability and stigma receptivity in Lilium during anthesis. Euphytica (2017) 213:231.

IBEGE - INSTITUTO BRASILEIRO DE GEOGRAFIA E ESTATÍSTICA. Produção da extração vegetal e da silvicultura. 2018. Disponível em: https://biblioteca.ibge.gov.br/visualizacao/ periodicos/74/pevs_2018_v33.

Johansen (1940). Plant microtechnique. New York: Mcgraw-Hill Book, 1940. 523 p.

Langkamp (1987). 'Germination of Australian Native Plant Seed.’ (Inkata Press: Melboume.).

Larcombe et al. (2016) On the persistence of reproductive barriers in Eucalyptus: the bridging of mechanical barriers to zygote formation by F1 hybrids is counteracted by intrinsic post-zygotic incompatibilities. Annals of Botany 118: 431-444, 2016

Luqman et al. (2019) Micromorphological observation of seed coat of Eucalyptus species (Myrtaceae) using scanning electron microscopy technique. Microsc Res Tech. 2019;82:75-84.

Martins et al. (2014). Germinação de sementes de eucalipto sob estresse hídrico e salino. Bioscience Journal, Uberlândia, v. 3, p. 318-329, 2014.

O'Brien and McCully (1981). The study of plant structure: principles and selected methods. Melbourne: Termarcarphi Pty, 1981.316 p.

Pereira (2002). Alternativas para aumentar a eficiência dos cruzamentos em programas de melhoramento de Eucalyptus. CERNE, V. 8, N.2, p.060-069, 2002.

Santos et al. (2017). Evaluation of costs of harvester in cut and processing of eucalyptus wood. Revista Árvore, Viçosa, v. 41, n. 5, p. 1-9, 2017. 